First, the institutions must know what is needed and the knowledge can be acquired only by close relations with the industries. Teachers should have ready access to the industries and their work for themselves and their students. Problems should be submitted for the research laboratories and needed means and materials provided. Such cooperation must certainly lead to important progress, not only in the industries, but in the related sciences, and progress under such circumstances is inevitable. May the influences which control have free course, and be not only justified but glorified.

\section{WM. MCMURTRIE}

\section{THE PROGRAM OF THE INTERNATIONAL COMMISSION ON THE TEAOHING OF $M A T H E M A T I O S^{1}$}

"IF we could first know where we are and whither we are tending, we could better judge what to do and how to do it." These words of Lincoln, like the words of many another genius, adapt themselves to divers situations. This statement epitomizes what the International Commission on the Teaching of Mathematics is to do. The first purpose of this body is to investigate the actual state of the teaching of mathematics in the various countries, and the second purpose is to discover the tendencies of the changes effected during the last two decades. Both of these investigations are to be made with a view to determining " what to do and how to do it." In the language of the central committee the aim of the commission is to suggest those general principles which should guide the teacher rather than to provide programs which should be adapted at the same time to the schools of all countries.

To Professor David Eugene Smith, of Columbia University, belongs the credit of having first suggested the formation of such a commission in the French mathematical journal, L'Enseignement Mathematique, in

${ }^{1}$ The complete Preliminary Report appeared in L'Enseignement Mathematique, and a translation by the author (of this article) in School Science and Mathematics, February, 1909.
1905 and again at the International Congress of Mathematicians at Rome in April, 1908. This congress authorized a committee consisting of Professor Felix Klein, Göttingen, Germany; Professor Sir George Greenhill, London, and Profesor H. Fehr, Geneva, Switzerland, to form an international commission. Those countries which have been represented at certainly two of the international congresses of mathematicians, with an average of at least two members, are entitled to representation on the active membership of the commission, while other countries are invited to be represented by associate members. The national delegations are urged to affliate with themselves national subcommissions, comprising representatives of the various stages of the teaching of mathematics in the general schools and in the technical and professional schools.

General direction is lodged in the original committee of three, Klein, Greenhill and Fehr. The official organ is L'Enseignement Mathematique, and the official languages are English, French, German and Italian.

The whole field of mathematical instruction, from the earliest primary work to the higher mathematics of the universities, is to be included in the investigation. A large place will be given to applied mathematics for technical and professional schools.

The work of the commission will be based upon the reports of the delegations, which are to be made out with the aid of the national subcommissions in conformity with the general plan fixed by the central committee of three. In the first part of these reports will be given a view of the actual scheme of studies, the corresponding examinations, the methods of teaching and the preparation of the teaching body. In the second part will be presented the actual tendencies of the instruction.

The aim of the mathematical instruction in the different types of schools-primary, secondary, trade schools, normal schools and teachers' colleges, and colleges and universitieswill be discussed. Should the aim of the instruction be the development of the mathematical faculties, or logical reasoning, or 
should the ends to be attained be purely practical?

Necessarily also some large educational problems are touched which concern the whole school organization. Mention may be made of the new types of schools and of the subject of coeducation.

The committee proposes to examine anew and with care what are the branches of this science most able to contribute to general culture. What is the necessary minimum in arithmetic, algebra, geometry and trigonometry, as well as in descriptive and projective geometry, analytic geometry and the calculus? What new ideas must be introduced and what old ones should be discarded?

The much-discussed laboratory method of teaching mathematics requires close inspection. Are there not inconveniences and dangers that result? In what measure may the conventional limits which exist between certain subjects of pure mathematics be made to disappear? What have been the results of the attempts to teach algebra and geometry together? geometry and trigonometry? differential and integral calculus? Careful study needs to be made of the points of contact of mathematics with drawing, with the applied sciences, with philosophy, and with the problems of daily life.

To what extent should paper-folding, observational geometry, logarithms, graphics in algebra and the slide rule be used? Those who desire a close relation between mathematics and physics ought to show exactly what geometrical notions have a direct bearing on physics and to cite those problems of elementary physics which require simultaneous linear equations, equations of the second degree in one or more unknowns, irrational quantities and progressions.

To what degree is it possible to accord a larger place to the historical development of mathematics and to the history of the teaching of mathematics? The extensive literature on mathematical recreations might be made useful. What are the means which will give mathematics a better place in popular instruction and enable the subject to overcome popular prejudices?
The progress of teaching depends directly on the preparation of the teachers. So the committee believes that it will be useful to take account of the reforms, actual or projected, which have in view the training of teachers conformably to modern conditions. In this connection the sex of the teacher for different schools, the introduction of the teacher to scientific research, and the amount of character of the pedagogical training are questions of fundamental importance.

The high plane of this investigation is indicated by the scientific standing of the three members of the central committee as well as by the personnel of the American delegation. These men are announced by Professor Klein to be the following: Professor William F. Osgood, Harvard University; Professor David Eugene Smith, Columbia University; Professor J. W. A. Young, Chicago University.

Preliminary work is to be begun immediately; the commission as a whole to meet during the Easter recess of 1911 preliminary to making a final report to the International Congress of Mathematicians, which is to meet at Cambridge, England, in 1912.

Some may regard the work of the commission as initiating a great reform movement. Reform does not come by commission; rather this development emphasizes the great movement towards vital instruction which has been in progress for over a century. The important work of the commission will be to gather together the valuable contributions from all the world and to make them available to all the world. To select the good and discard the worthless is no small task but one well worthy of the best efforts of the leaders in mathematical thought.

UNiversity of MrChigan,

\section{C. KarPinski}

ANN ARBor, Mich.

\section{LIEUTENANT SHACKLETON'S ANTARCTIC EXPEDITION}

The Wellington, New Zealand, correspondent of the London Times, has cabled some details of the scientific results of the Shackleton expedition.

The frozen glacier-eroded lakes near Cape 